Коровина О. В.

Дневник как практика культурно-исторической рефлексии (инициативы А. В. Никитенко)

Пушкинская библиотека-музей Централизованной библиотечной системы г. Белгорода, ул. Ватутина, д. 4, г. Белгород, 308013, Россия;olga-helga.1987@yandex.ru

Аннотация. В настоящее время наблюдается рост внимания научного мира к изучению автобиографических жанров. Такой интерес обусловлен тем, что автобиографии позволяют исследовать самосознание человека через свидетельства о себе без посредников в разных аспектах, применяя различные методы гуманитарных наук. Большая ценность дневника профессора СанктПетербургского университета, действительного члена Академии наук, цензора Александра Васильевича Никитенко как источника исторических сведений признана давно. В двухтысячных годах ученые, признав историографический подход кдневнику Никитенко недостаточным, стали изучать его с литературоведческих позиций; культурно-философский же подход к этому личному документу еще не найден. В исследовании, представленном в статье, использовались сравнительно-исторический, историко-культурный, герменевтический и онтологический подходы и методы. Дневник А.В. Никитенко занимает особое положение в обширном корпусе российской дневниковой литературы. Это культурно-историческая рефлексия на общественную жизнь XIX века и осмысление своего места в этой жизни. Рефлексия внутренней жизни автора дневника не выходит за пределы обозначенной им самим доктрины и является отражением собственных реакций и установок на всё ту же жизнь общественную.

Ключевые слова: дневник; А.В. Никитенко; автобиография; русская литература XIX в.; культурно-историческая рефлексия; общественная жизнь в России XIX века.

Для цитирования: Коровина О. В. Дневник как практика культурноисторической рефлексии (инициативы А.В. Никитенко) // Научный результат. Социальные и гуманитарные исследования. 2020. Т. 6. № 1. С. 59-65. DOI: 10.18413/2408-932X-2020-6-1-0-6

\title{
O. V. Korovina \\ Diary as a practice of cultural-historical reflection (initiatives of A. V. Nikitenko)
}

Pushkin Library-Museum of the Centralized Library System of Belgorod, 4 Vatutin St., Belgorod, 308013, Russia; olga-helga.1987@yandex.ru

Abstract. Currently, there is a growing attention of the scientific world to the study of autobiographical genres. This interest is due to the fact that autobiographies allow the researcher to study a person's self-consciousness through evidence about themselves without intermediaries in different aspects of the humanities, using different approaches and methods. The great value of the diary of a Professor of St. Petersburg 
University, a full member of the Academy of Sciences, censor Alexander V. Nikitenko as a source of historical information has long been recognized. In the 2000-s scientists began to study it from literary positions, recognizing that the historiographical approach to the diary of Nikitenko was insufficient. But the cultural and philosophical approach to this personal document has not yet been found. The study presented in the article used comparative-historical, historical-cultural, hermeneutic and ontological approaches and methods. The diary of Alexander Nikitenko occupies a special position among the vast body of Russian diary literature. Nikitenko's diary is an extensive cultural and historical reflection on the social life of the $19^{\text {th }}$ century and understanding of its place in this life. The reflection of the inner life does not go beyond the doctrine indicated by the author himself and is a reflection of his own reactions and attitudes to the same social life.

Keywords: diary; Alexander V. Nikitenko; autobiography; Russian literature of the $19^{\text {th }}$ century; cultural and historical reflection; Russian public life in the $19^{\text {th }}$ century

For citation: Korovina O. V. (2020), "Diary as a practice of cultural-historical reflection (initiatives of A.V. Nikitenko)", Research Result. Social Studies and Humanities, 6 (1), 59-65, DOI: 10.18413/2408-932X-2020-6-1-0-6

Дневник профессора Санкт-Петербургского университета, действительного члена Академии наук, цензора Александра Васильевича Никитенко занимает особое положение среди обширнейшего корпуса российской дневниковой литературы. Помимо значительной историко-культурной ценности, он осознается учеными как образец литературного жанра и культурноисторической рефлексии, которая, применительно к автобиографической прозе Никитенко, еще нуждается в изучении.

Прежде чем стать практикой культурно-исторической рефлексии, дневниковая форма повествования прошла долгий путь длиною в несколько столетий. Осуществляя культурно-исторический обзор развития автобиографизма, мы не используем жесткое жанровое разграничение мемуаров, дневников, воспоминаний и автобиографий. Обобщая эти жанры в единый документальный массив автобиографической литературы, мы применяем по отношению к нему понятие «мемуаристика», а также вошедшие в научный обиход сравнительно недавно понятия «эгодокументы» и «личные документы».

Исследователь жанра дневника О.Г. Егоров считает его прообразом «Размышления» римского императора Марка Аврелия (Егоров, 2002). О близости этого произведения к дневниковому жанру говорит его ориентированность на внутреннее «я», однако «Размышления» не содержат описания событий внешней жизни, которые характерны для дневникового жанра в традиционном его понимании. В данном исследовании мы не будем касаться автобиографических моментов в сочинениях авторов европейского средневековья (Аврелий Августин, Пьер Абеляр), но обратимся к дневниковой практике культурно-исторической рефлексии на русской почве.

Минимальные элементы автобиографического характера исследователи находят уже в литературных образцах Древней Руси, однако религиозное мировоззрение древнерусского человека противоречило публичному высказываю личных переживаний и мнений. Тщательное изучение летописных сводов может обнаружить личный взгляд автора в них на те или иные события, но это - исключение из правил. Как отмечал Д.С. Лихачев, безличностный характер средневекового исторического повествования, довлевший в древнерусской литературе, препятствовал развитию мемуаристики (Лихачева, Лихачев, 1971: 52-70). Известный исследователь древнерусской литературы Н.К. Гудзий первыми образцами автобиографического повество- 
вания на русской почве называет «Поучение Владимира Мономаха» (XII в.) и «Житие протопопа Аввакума» (XVII в.), в котором сочетаются жанр духовного завещания, исповеди и проповеди. Мотивы и цели, побуждающие к созданию собственного жизнеописания древнерусского человека и новоевропейской личности, были принципиально различны (Гудзий, 1934). «Там, где является попытка зафиксировать себя самого в покаянных тонах в свете нравственного долженствования, возникает первая существенная словесной объективации жизни исповедь» - пишет М.М. Бахтин - «В самоотчете-исповеди нет героя и нет автора, ибо нет позиции для осуществления их взаимоотношения, позиции ценностной вненаходимости; герой и автор слиты воедино» (Бахтин, 1979: 124).

Петровские преобразования русского общества способствовали усилению светскости русской литературы и смене мировоззренческих позиций, что привело к формированию автобиографизма и проникновению его в жанры путевых заметок и дневников, духовных завещаний, исповедей, а также к развитию мемуарного жанра. Предметом, достойным изображения, становится уже не только героический подвиг, историческое событие или жизнеописание выдающегося деятеля, но и личные переживания выходца из любого сословия. Автор XVIII века уже видит ценность человеческой личности, ее жизненного опыта и фиксации событий текущей жизни. Однако автобиографическая литература XVII века гораздо менее обширна, чем литература века XIX-го. 153 произведения мемуаристики за восемнадцатое столетие находит известный исследователь этого жанра А.Г. Тартаковский (Тартаковский, 1997: 183). Всеобщая установка петровского общества на «государственное служение» и «общую пользу» противоречила установке на индивидуализацию личности и отражению этого процесса в литературе. Для мемуариста XVIII в. его личная история неотделима от семейной истории, истории рода и предков. Обнаружение многих поколе- ний позади себя занимало значительное место в содержании мемуарных произведений того времени. Во второй половине XVIII в. авторы личных документов целью их создания видят укрепление семейных связей и традиций. Среди предполагаемых читателей эго-документа лишь члены семьи и потомки автора, но никак не посторонние лица, поэтому установка на публикацию личного документа при жизни автора отсутствовала.

Уже в начале XIX в. взгляд авторов на создание личных документов меняется: в написание автобиографических сочинений вкладывается новый, не обнаруживающийся ранее смысл. Это и стремление к осознанию своей личности в ходе истории, и стремление к самопознанию, и ряд других психологических потребностей, подробно описанных в книге О.Г. Егорова «Русский литературный дневник XIX в. История и теория жанра» (2003). Изменению отношения образованного общества к личным документам способствовала активизация общественной жизни во всех сферах, связанная с надеждами на новые либеральные реформы Александра I.

Подчеркивая историзм мемуаристики первой половины XIX в., А.Г. Тартаковский делает акцент на развитии исторического сознания общества и слиянии биографии автора с историческим процессом. Учеными выделяются и другие факторы, способствующие расцвету дневникового жанра в XIX в.: это и высокий уровень письменной культуры, и рост образования (см.: Тартаковский, 1997). Дневник становится выражением творческих потребностей и инструментом формирования литературного слога для начинающих литераторов. По справедливому замечанию О.Г. Егорова: «Дневник перестает быть элементом частной жизни и литературного быта и становится частью литературного процесса» (Егоров, 2002: 68).

Разделяя биографии на ориентированные на поддержание общепринятых норм и представлений о человеческом благе и те, внутри которых проблематизируются прежние ценности и задаются новые идей- 
ные представления о благе, Д.Я. Калугин подчеркивает, что второй «вид жизнеописаний становится актуальным в эпохи, когда возникает необходимость рефлексии над собственным опытом, а жизнь утрачивает однозначность и предзаданность» (Калугин, 2006: 180). Дневниковая биография А.В. Никитенко, в силу прогрессивных взглядов ее автора и жизненных ситуаций, в которых он оказывался благодаря своему деятельному отношению к жизни, вне всяких сомнений должна быть отнесена ко второму типу биографий, выделяемому Калугиным.

Автодокументальная проза А.В. Никитенко состоит из созданной в 1851 году «Моей повести о самом себе и о том, чему свидетель в жизни был» и Дневника, который Александр Васильевич вел с 1825 по 1877 годы. Начиная изучение конкретных образцов автобиографической литературы, следует конкретизировать их жанровые особенности. Если «Моя повесть...» создавалась Никитенко на основе воспоминаний о детских и юношеских годах и вследствие временной удаленности от описываемых событий может быть отнесена к мемуарному жанру, то дневник создавался Александром Васильевичем синхронно с происходящим в жизни в то время, когда в России «сформировались все основные жанровые особенности дневника» (Егоров, 2002: 69). Большая ценность дневника Никитенко как источника исторических сведений признана уже очень давно. В двухтысячных годах ученые, признав, историографический подход к дневнику Никитенко недостаточным, стали изучать его, прежде всего, с литературоведческих позиций (И.И. Кулакова, О.Г. Егоров), культурно-философский же подход к этому личному документу еще не найден.

Один из первых вопросов, который непременно возникнет перед исследователем дневника конкретного человека - цель и причины его создания. О.Г. Егоров, осуществляя классификацию дневников, выделяет группу дневников, которая служит «заместителем тех содержаний психики, которые по той или иной причине не могут быть выражены другим способом», а также дневников, созданных в условиях, «связанных слишением свободы их авторов», - в этом случае они также обладают «заместительной» функцией (Егоров, 2002: 5-6). Продолжением этой мысли будет являться высказывание профессора В.К. Кантора. Рассуждая о личности А.В. Никитенко, он пишет: «Есть люди, остающиеся в истории как яркие звезды совсем не благодаря той деятельности, которая была у всех на виду, а наоборот тем, что делалось для души, наедине с самим собой, где человек был абсолютно свободен» (курсив мой. - О.К.) (Кантор, 2006: 111-112). Стремление к свободе самовыражения, постоянный (пожизненный) поиск свободы - не это ли одна из причин ведения Александром Васильевичем дневника на протяжении почти шестидесяти лет, начиная с четырнадцатилетнего возраста и заканчивая предпоследним днем жизни? Рожденный в крепостной неволе, ставший служителем самой «несвободной» сферы службы- цензуры, сам, по сути, ставший ограничителем свободы выражения на страницах печати для многочисленных творцов русского литературного слова, но при этом стремившейся к совершенствованию цензурной системы изнутри, в своем личном документе, может быть, единственном своем «свободном» документе, выразил стремление к освобождению личности от внешних и внутренних оков. В 1827 году, когда студенту Императорского Санкт-Петербургского университета Александру Никитенко в числе двадцати лучших студентов предложат отправиться в Берлин для «усовершенствования их познаний с тем, чтобы, возвратясь, они могли занять профессорские кафедры» (трудиться затем в качестве профессора 14 лет - было обязательным условием этой поездки), автор дневника запишет: «не могу примириться ни с чем, что хоть сколько-нибудь отзывает закрепощением себя. Раны от неволи еще слишком свежи во мне для того, чтобы я добровольно согласился 
еще раз испытать ее на себе, хотя бы и в смягченном и облагороженном виде. Соблазн усовершенствоваться в Германии, конечно, велик, но я предпочитаю свободно располагать своей будущностью в России» (Никитенко, 1955a: 61-62). Уже в 1875 году: «Единственный оплот против внутренних колебаний и разных страхов, против всяких мелочей и дрязг ежедневных - это внутренняя свобода» (Никитенко, 1956: 339). Концепт «свободы» личной, к которой столь неравнодушно относился Никитенко, и свободы как общественноправовой категории проходит через весь его дневник. Присутствуют в дневнике и замечания, указывающие не только на личную несвободу, но и несвободу дворянского общества, а порой и на противоречие понятий свободы и общества: «общество это в полной зависимости от известных, временно преобладающих условий», «ты хочешь быть свободен - так ты в войне с обществом» (Никитенко, 1955: 126).

В статье «Горчащий привкус ума» В.Л. Глазычев отмечает редкостную способность Никитенко к рефлексивному анализу, «обращенному как на внешние события, в силу чего он умел видеть существо явлений, не обманываясь их упаковкой, так и на самое себя, не принижая своих усилий, но и не страдая головокружением от собственной значительности» (Глазычев 2006). О.Г. Егоров отказывает Никитенко в рефлексии «в смысле скрупулезного анализа душевной жизни, свойственный интроверту» (Егоров, 2002: 82). И с этими обоими утверждениями трудно не согласиться.

С одной стороны, Дневник А.В. Никитенко - это фиксация событий общественной жизни и обнаружение себя в этих событиях. Сферу личных переживаний, семейной жизни Александр Васильевич практически не затрагивает. Запись, завершающая фиксацию событий 1833 года: «Вот уже месяц, как я женат» (Никитенко, 1955a: 130). Эта предельно лаконичная фраза воспринимается очень неожиданно, поражает своей краткостью и отсутствием описания каких бы то ни было деталей этого важного события, дневник затем прерван на четыре месяца, возобновлен 1 января. Начинать год с дневниковой записи было характерно для А.В. Никитенко.

Культурно-историческая рефлексия в дневнике А.В. Никитенко осуществлялась, главным образом, над областью общественной жизни России, государственной службы, цензурного дела, процессом образования и преподавания в высших учебных заведениях. И в то же время автор Дневника четко видит и фиксирует свою личность в этих институциях, называя себя доктринером и следуя выработанной им концепции как во внешней, так и во внутренней жизни. Не случайно ученые В.К. Кантор и О.Г. Егоров, вслед за Д.С. Мережковским, сравнивают Никитенко с мыслителями-стоиками. Александр Васильевич на страницах дневника обозначает свое понимание высших достоинств человека: стойкость, самообладание, мужество. Он упорно стремится к достижению этих состояний, по собственному признанию, чуть ли не с детства многократно афористично фиксируя их в дневнике, как самовнушение, как девиз.

«Самообразование, беспрерывное самоусовершенствование, внутреннее самоустройство в видах возможного умственного и нравственного возвышения вот великая задача, вот труд, который стоит величайших усилий (1854 г.) (Никитенко, 1955a: 396). «Самая необходимая вещь для человека - самообладание» (1857 г.) (Никитенко, 1955a: 460), «всё, чем человек укрощает свои страсти и возвышается до самообладания, самоуправления, до высшего понимания себя и своей жизни (Никитенко, 1955б: 144) «Воздельввай разумно самого себя - вот истинная задача духа». (1862 г.) (Никитенко, 1955a: 303). Сдержанность, мужество, самообладание. Не вызывай на бой судьбы, не рисуйся перед ней своею храбростью - это глупо, а покоряйся и терпи с достоинством мужа и человека и с уверенностью философа, что жизнь вовсе не заслуживает той важности, какую мы ей даем». (1863 г.) (Никитенко, 1955б: 310). «Держись крепче за что-нибудь, да, держись, чтобы вот этот 
прилив и напор темных мыслей не увлек тебя в бездну. Характер, нравственное самообладание, свобода- ведь это те старые ступени, на которых ты думал всегда основать и утвердить себя: неужели они сгнили и подломились?» (1864 г.) (Никитенко, 1955а: 469). «Самопознание, самообладание, самоуправление - какие трудные и какие необходимые задачи для человека, стремящегося к самоусовершенствованию!» (1868 г.) (Никитенко, 1956: 134). «Работая над самим собою, я всё еще стараюсь расширять круг моих понятий, пополнять кое-какие мои познания, а главное - обставлять мой характер укреплениями так, чтобы в него не могли проникать и его колебать никакие внешние враждебные влияния. В поведении самообладание и сдержанность» (1872 г.) (Никитенко, 1956: 253-254). Одна достойнейшая цель мыслящего человека - это нравственное самообразование и образование характера. К этому стремился целую мою жизнь, и хотя, конечно, не успел далеко удовлетворить идеалу того и другого, однако я не могу упрекать себя за эту односторонность и теперь остаюсь при том убеждении и при тех же усилиях (Никитенко, 1956: 292-293).

Автор описывает в дневнике свои наблюдения светской и культурной жизни, образовательного процесса и результаты своей деятельности в преподавательском деле. Записи, завершающие 1841 год, открывают череду пессимистических рассуждений, связанных в первую очередь с положением дел цензуры, образования и общественной жизни: «Проклято время, где существует выдуманная, официальная необходимость моральной деятельности без действительной в ней нужды, где общество возлагает на вас обязанности, которые само презирает...» (Никитенко, 1955a: 240). Эта позиция прослеживается на протяжении всего дневника.

Распоряжения правительства, любые изменения, происходящие в области цензуры Никитенко фиксирует в дневнике даже не находясь в должности цензора. После пятнадцатилетней цензурной практики он становится теоретиком цензуры, про- должает участвовать в цензурной жизни уже в качестве члена различных комитетов по цензуре и книгопечатанию, а также составителя изменений к цензурным уставам и инструкции для цензоров. Не изменив своим либеральным позициям, уже в конце дневника, не проводя подробный анализ своей многолетней цензурной деятельности, автор противопоставляет «запретительные меры» правительства своей «защитительной» работе в области цензурного законодательства (Березина, 2000: 6084). Рефлексии Никитенко по поводу культурных, литературных и образовательных процессов безусловно представляют не меньший интерес, чем осмысление им цензурной деятельности. Но их анализ - это предмет отдельного исследования.

Дневник Никитенко - это обширная культурно-историческая рефлексия общественной жизни XIX века и осмысление своего места в этой жизни. Рефлексия внутренней жизни постоянно присутствует, но не выходит за пределы обозначенной самим автором доктрины и является отражением собственных его установок на жизнь общественную.

\section{Литература}

Бахтин, М.М. Автор и герой в эстетической деятельности. Смысловое целое героя // Эстетика словесного творчества. М., 1979. C. 9-190.

Березина, В.Г. «У мысли стоя на часах...: Цензоры России и цензура». СПб.: Издво СПбГУ, 2000. 259 с.

Глазычев, В.Л. «Горчащий привкус ума» [Электронный pecypc] URL: http://www.glazychev.ru/publications/reviews/200 6-03_gor4aschy_privkus_uma.htm (Дата обращения: 5.06.2019).

Гудзий, Н.К. Комментарий // Житие протопопа Аввакума им самим написанное и другие его сочинения. [М.]: Academia, 1934. C. 371-474. [Электронный pecypc] URL: http://feb-web.ru/feb/avvakum/texts/a34/a34-371.htm (Дата обращения: 01.0.2019).

Егоров, О.Г. Дневники русских писателей XIX века: Исследование. М.: Флинта, Наука, 2002. 288 с.

Калугин, Д.С. Русские биографические нарративы XIX века: от биографии частного 
лица к истории общества // История и повествование. Под ред. Г.В. Обатнина и П. Песонена. Москва-Хельсинки: Новое литературное обозрение. 2006. С. 178-195.

Кантор, В.К. А. В. Никитенко: русский либерал как наследник петровских реформ // Вопросы философии. 2006. № 11. С. 111-112.

Лихачева, В.Д., Лихачев, Д.С. Своеобразие древнерусской литературы // Художественное наследие Древней Руси и современность. Л.: Наука, 1971. С. 52-70.

Никитенко, А.В. Дневник в 3 т. / [Подготовка текста, вступ. статья и примеч. И.Я. Айзенштока]. Т. 1. М.: Гослитиздат, 1955. $541 \mathrm{c}$.

Никитенко, А.В. Дневник в 3 т. / [Подготовка текста, вступ. статья и примеч. И.Я. Айзенштока]. Т. 2. М.: Гослитиздат, 1955. $650 \mathrm{c}$.

Никитенко, А.В. Дневник в 3 т. / [Подготовка текста, вступ. статья и примеч. И.Я. Айзенштока]. Т. 3. М.: Гослитиздат, 1956. 581 c.

Тартаковский, А.Г. Русская мемуаристика и историческое сознание XIX века. М.: Аpхеографический центр, 1997. 356 с.

\section{References}

Bakhtin, M. M. (1979), "Avtor i geroj v esteticheskoj deyatelnosti. Smyslovoe celoe geroya" [Author and hero in aesthetic activity. The semantic whole of the hero], Estetika slovesnogo tvorchestva [Estetika of verbal creativity], Iskusstvo, Moscow, Russia, 9-190 (in Russ.).

Berezina, V. G. (2000), U mysli stoya na chasax...: Cenzory 'Rossii i cenzura [Stand guard over thoughts...: Russia's Censors and censorship], Publishing house of Petersburg University, St.Petersburg, Russia (in Russ.).

Egorov, O. G. (2002), Dnevniki russkikh pisatelej 19 veka: Issledovanie. [Diaries of Russian writers of the $19^{\text {th }}$ century: Study.], Flinta, Moscow, Russia. 177 pp. (in Russ.).

Glazychev, V. L. (2006), Gorchashchij privkus uma [Online] URL:http://www.glazychev.ru/publications/revie ws/2006-03_gor4aschy_privkus_uma.htm (Accessed: 5 June, 2019).

Gudziy, N. K. (1934), Kommentarij in: Zhitie protopopa Avvakuma im samim napisannoe $i$ drugie ego sochineniya [The life of Protopope Habakkuk himself and his other writings] [Online] URL: http://feb- web.ru/feb/avvakum/texts/a34/a34-371-.htm (Accessed: 1 June, 2019).

Kalugin, D. S. (2006), "Russian biographical narrative of the twentieth century: from the biography of an individual to the history of society", Istoriya i povestvovanie [History and storytelling], in Obatnin, I.P (ed.), Novoe literaturnoe obozrenie, Moscow-Xel`sinki, Russia, 178-195 (in Russ.).

Kantor, V. K. (2006), “A.V. Nikitenko: Russian liberal as heir to Peter's reforms", $V o$ prosy Filosofii [Question of Philosophy], 11, 111112 (in Russ.).

Likhachyova, V. D. and Likhachyov, D. S. (1971), "The originality of old Russian literature", Khudozhestvennoe nasledie Drevnej Rusi i sovremennost ' [Artistic heritage of Ancient Russia and modernity], Nauka, Leningrad, Russia, 52-70 (in Russ.).

Nikitenko, A. V. (1955), Dnevnik v 3 tomakh. T. 1 [Diary in3 vol.], in Aizenshtok, I.Ya. (ed.), 1, Goslitizdat, Moscow, Russia (in Russ.).

Nikitenko, A. V. (1955), Dnevnik $v 3$ tomakh. T. 2 [Diary in 3 vol.], in Aizenshtok, I.Ya. (ed.), 2, Goslitizdat, Moscow, Russia (in Russ.).

Nikitenko, A. V. (1956), Dnevnik v 3 tomakh. T. 3 [Diary in 3 vol.], in Aizenshtok, I.Ya. (ed.), 3, Goslitizdat, Moscow, Russia (inRuss.).

Tartakovsky, A. G. (1997), Russkaya memuaristika $i$ istoricheskoe soznanie XIX veka. [Russian memoirs and historical consciousness of the $19^{\text {th }}$ century], Arxeograficheskij centr, Moscow, Russia (in Russ.).

Информация о конфликте интересов: автор не имеет конфликта интересов для деклараций.

Conflict of Interests: the author has no conflict of interests to declare.

\section{OБ АВТОРE:}

Коровина Ольга Вячеславовна, заведующая музейным отделом Пушкинской библиотеки-музея Централизованной библиотечной системы г. Белгорода, ул. Ватутина, д. 4, г. Белгород, 308013, Россия; olgahelga.1987@yandex.ru

\section{ABOUT THE AUTHOR:}

Olga V. Korovina, Head of the Museum Department of the Pushkin Library-Museum of the Centralized Library System of Belgorod, 4 Vatutin St., Belgorod, 308013, Russia; olgahelga.1987@yandex.ru 